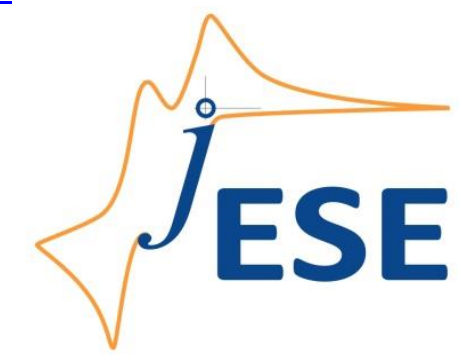

Open Access: ISSN 1847-9286

www.jESE-online.org

Original scientific paper

\title{
Poly (DL-valine) electro-polymerized carbon nanotube paste sensor for determination of antihistamine drug cetirizine
}

Tigari Girish ${ }^{1}$, Jamballi G. Manjunatha ${ }^{1, 凶}$, Pemmatte A. Pushpanjali ${ }^{1}$, Nambudumada

S. Prinith ${ }^{1}$, Doddarasinakere K. Ravishankar ${ }^{2}$ and Gurumallappa Siddaraju ${ }^{3}$

${ }^{1}$ Department of Chemistry, FMKMC College, Madikeri, Mangalore University Constituent College, Karnataka, India

${ }^{2}$ Department of Chemistry, Sri. Mahadeshwara Government First Grade College, Kollegal,

Chamarajanagar, Karnataka, India

${ }^{3}$ Department of Chemistry, JSS College for Women, Chamarajanagar, Karnataka, India

Corresponding author: ${ }^{\bowtie}$ manju1853@gmail.com; Tel: +91-0827222833

Received: November 18, 2020; Revised: December 11, 2020; Accepted: December 12, 2020

\begin{abstract}
Poly (DL-valine) modified multiwalled carbon nanotube paste sensor (PVLMCNTPS) was prepared by electro-polymerization route. PVLMCNTPS and bare multiwalled carbon nanotube paste sensor (BMCNTPS) morphologies and sensing properties for cetirizine (CTZ) were confirmed through a field emission scanning electron microscope (FE-SEM) and electrochemical studies, respectively. In contrast to BMCNTPS, PVLMCNTPS surface composite creates an electrocatalytic impact on the oxidation of CTZ. PVLMCNTPS properties were optimized using parameters such as accumulation time, number of polymerization cycles, solution $\mathrm{pH}$, and scan rate. The optimized PVLMCNTPS was applied for the determination of cetirizine in $0.1 \mathrm{M}$ phosphate buffer solution (PBS) of $\mathrm{pH} 7.0$, using cyclic voltammetry (CV). It is shown that PVLMCNTPS provides analytical linearity from 2.0 to $80 \mu \mathrm{M}$, with detection limit of $0.11 \mu \mathrm{M}$ for CTZ determination. PVLMCNTPS was found highly selective for CTZ in presence of some interfering organic molecules. The stable and selective PVLMCNTPS was applied for CTZ determination in pharmaceutical pills with satisfactory results.
\end{abstract}

\section{Keywords}

Polymer modified sensor; drug analysis; cyclic voltammetry

\section{Introduction}

Cetirizine (CTZ) is an antihistamine drug which is usually prescribed for allergic symptoms like running nose, itching, hives, watery eyes, body ache, etc. It acts as an allergy reliever by blocking 
histamine which is produced during allergic reactions in the human body. The overdose of CTZ can trigger many adverse effects such as stomach pain, tiredness, vomiting, diarrhea, drowsiness, etc., while in serious conditions, one may experience breathlessness [1-5]. Therefore, it is significant to develop the analytical tool for determination of CTZ drug. Drug testing and analysis are important in the quality and quantity control of pharmaceutical utilities, and therefore, fast, simple and effective analytical methods are required for the analysis of drug molecules [6]. There are many methods previously used for CTZ determination such as electrophoresis [7], high performance liquid chromatography [8], spectrophotometry [9], HPLC/MS [10], spectrofluorimetry [11], and electrochemical methods $[12,13]$. All these methods, except electrochemical methods, have some drawbacks like time consuming, requirements for more organic solvents and reagents, and experts for handling, and also inclusion of complicated and expensive procedures [14]. Nowadays, the field of interest has been focused on electrochemical devices and their applications, almost due to their benefits like low cost, simple sample preparations, low consumption of reagents and analytes, fast testing time, and portability with high sensitivity [15-20].

Looking from the aspect of materials for electrochemical sensors, one must mention multiwalled carbon nanotubes (MWCNTS). MWCNT is the widely used allotropy of carbon material for different applications including sensors, supercapacitors, drug delivery platforms, electronic chips, fuel cells, energy storage devices, additives in polymers, flat panel display, charge-discharge tubes, etc. [21-24]. To further improve their usefulness, MWCNTs are frequently modified. The high utility of modified MWCNTs is due to their enhanced electrical, thermal, mechanical, electronic, and stability properties [25-27]. Different modification techniques such as surfactant immobilization, electropolymerization, etc. have already been reported. Modification of a sensing electrode is usually performed to improve the sensing properties of electrodes [28-35].

In the present work, bare multiwalled carbon nanotube paste sensor (BMCNTPS) is coated with poly (DL-valine) through electro-polymerization. The formed poly (DL-valine) multiwalled carbon nanotube sensor (PVLMCNTPS) is used as a sensing surface for the determination of CTZ in real samples.

\section{Experimental}

\section{Instruments}

Model $\mathrm{CHI}-6038$ potentiostat (procured from USA) connected with three-electrode arrangement and a computer was used for all voltammetric measurements. The three-electrode system included a working electrode (PVLMCNTPS/BMCNTPS), a counter electrode (platinum wire) and a reference electrode $\left(\mathrm{Hg} / \mathrm{Hg}_{2} \mathrm{Cl}_{2}\right)$. All measurements were performed at laboratory temperature $\left(27 \pm 2{ }^{\circ} \mathrm{C}\right)$.

\section{Chemicals and preparations}

Riboflavin (RF), paracetamol (PC), and DL-valine (VL) were procured from Molychem, India. Cetirizine (CTZ) is procured from $\mathrm{TCI}$ Japan. Multiwalled carbon nanotubes were received from Sisco Laboratories LTD, Mumbai, India. The remaining chemicals were of AR grade. CTZ, RF, PC (10 $\left.10^{-4} \mathrm{M}\right)$ standard solutions were prepared using distilled water. Phosphate buffers standards of different $\mathrm{pH}$ were prepared by mixing $\mathrm{Na}_{2} \mathrm{HPO}_{4}(0.1 \mathrm{M})$ and $\mathrm{NaH}_{2} \mathrm{PO}_{4}(0.1 \mathrm{M})$.

\section{Sensors preparation}

BMCNTPS material was prepared by physical mixing of multiwalled carbon nanotubes and silicone oil in a proportion of 60:40 for $20 \mathrm{~min}$. The obtained uniform paste was filled into the cavity of Teflon rod pre-inserted with copper wire for electrical connection. Surface of electrode was 
polished with a tissue to provide uniform surface and to avoid disturbance in electrochemical measurements.

\section{Results and discussion}

\section{Preparation of PVLMCNTPS through electro-polymerization}

Electrochemical polymerization on BMCNTPS was performed by the potential scanning in PBS ( $\mathrm{pH}$ $5.5,0.1 \mathrm{M}$ ) containing $1.0 \mathrm{mM}$ DL-valine in the potential window -0.2 to $1.7 \mathrm{~V}$ with a scan rate of 0.1 $\mathrm{V} / \mathrm{s}$ (Figure 1a). As the number of scanning cycles passed, CV curves sloped down at positive potentials. This shows the formation of a polymer layer on electrode surface. The number of polymerization scans can affect the electrode properties, and so it was optimized by varying cycles from 5-20 as shown in Figure 1b. Five CV cycles were fine-tuned for CTZ sensing, while after 5 cycles the CV shape and peak current values declined. The structure of electro-generated poly (DL-valine) is shown in Figure 1c.
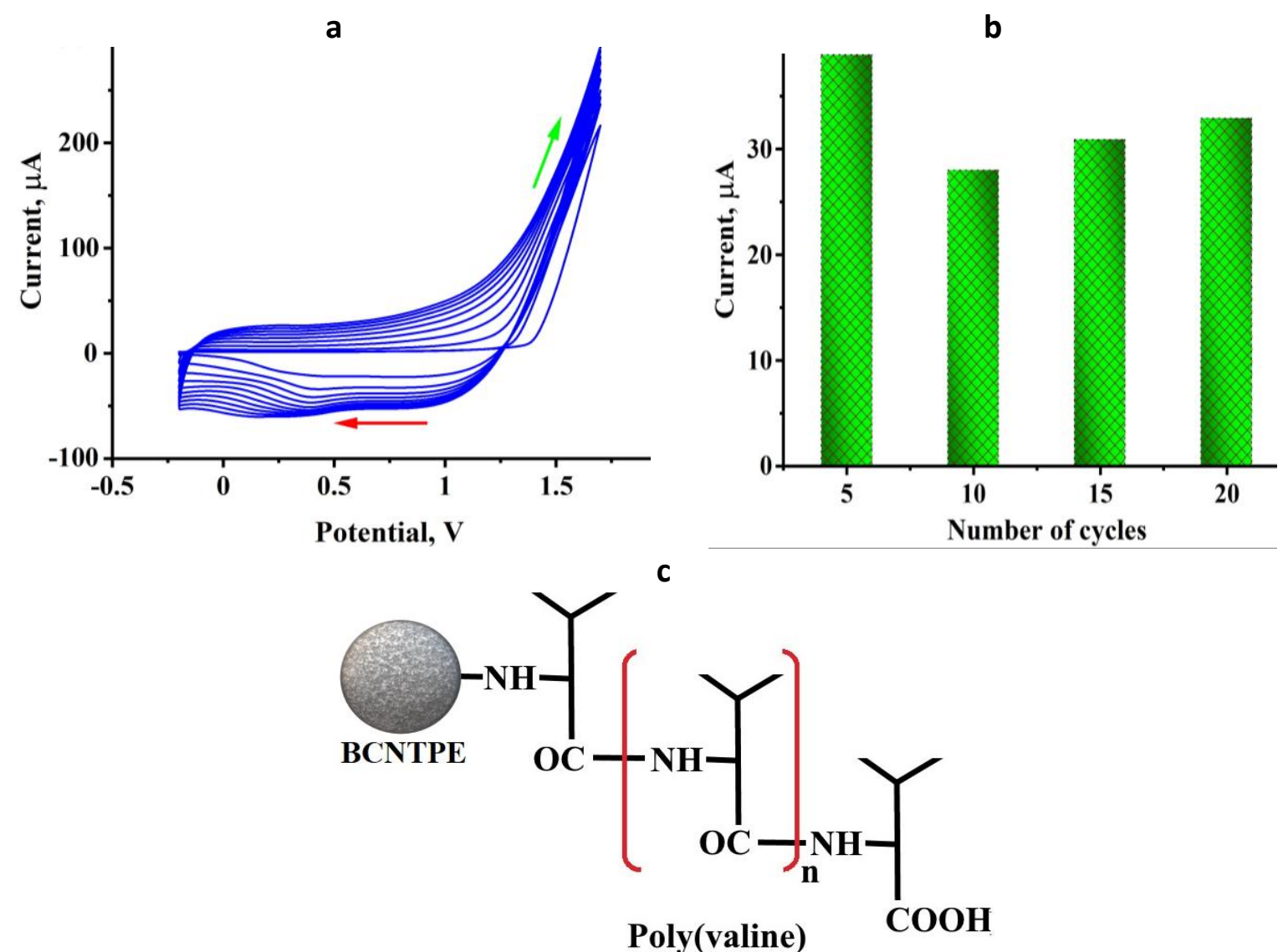

Figure 1. (a) Electrochemical polymerization of VL $(1.0 \mathrm{mM})$ at BMCNTP surface in $0.1 \mathrm{PBS}, \mathrm{pH} 5.5$ with scan rate $0.1 \mathrm{~V} / \mathrm{s}$; (b) peak current values of CTZ response against the number of polymerization cycles; (c) structure of electro-generated poly (DL-valine) film on BMCNTP electrode surface.

\section{Surface characterization of sensors}

Figure 2 presents FESEM images of BMCNTPS and PVLMCNTPS surfaces, where rather different surface textures can be clearly seen. Whereas BMCNTPS shows arrangement of carbon layers with nanotubes on the surface, PVLMCNTPS provides a porous and fibrous morphology due to poly (DL-valine) layer growth on BMCNTPS. 

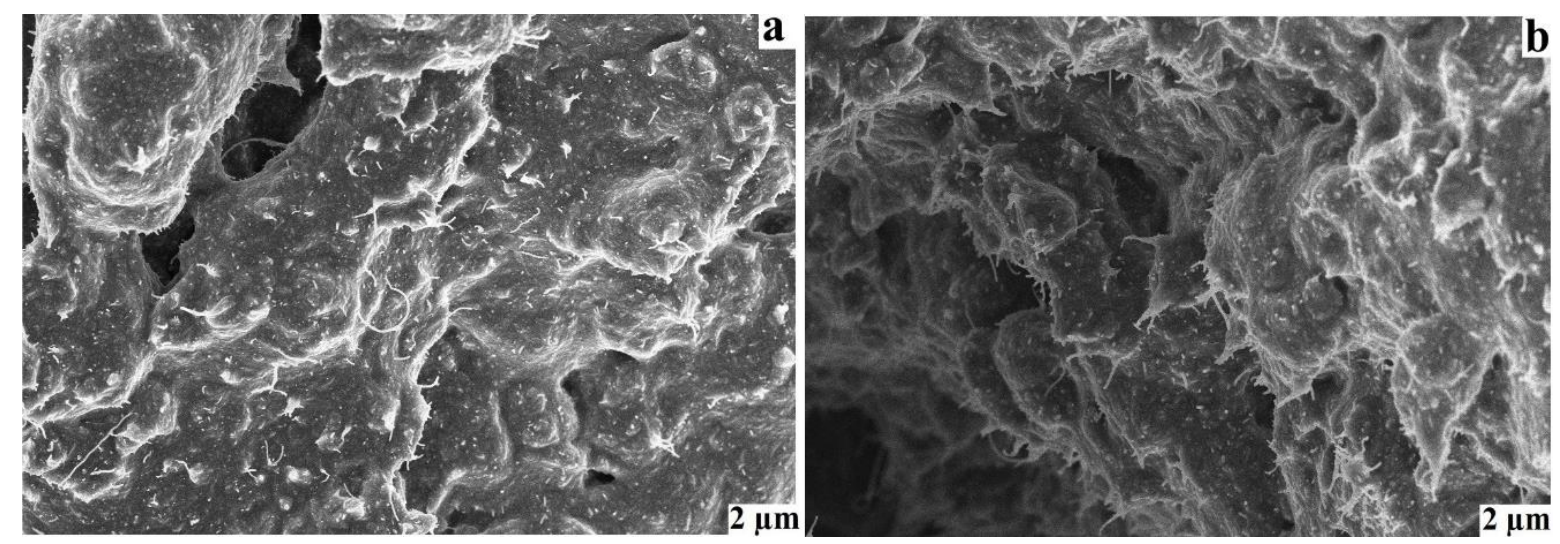

Figure 2. FESEM images of (a) BMCNTPS and (b) PVLMCNTPS.

Electrochemical characterization and calculation of effective surface area

Electrochemical characterizations of BMCNTPS and PVLMCNTPS were performed in $0.1 \mathrm{M} \mathrm{KCl}$ containing $2.0 \mathrm{mM}\left[\mathrm{Fe}(\mathrm{CN})_{6}\right]^{3-/ 4-}$ redox system using $\mathrm{CV}$ at $0.1 \mathrm{~V} \mathrm{~s}^{-1}$ scan rate, as depicted in Figure 3. BMCNTPS surface interaction with $\left[\mathrm{Fe}(\mathrm{CN})_{6}\right]^{3-/ 4-}$ gives poor current signals with higher separation of peak potential values $\left(\Delta E_{\mathrm{p}}\right)$. At the other side, PVLMCNTPS gives higher current response with lower $\Delta E_{\mathrm{p}}$ upon interaction with $\left.\mathrm{Fe}(\mathrm{CN})_{6}\right]^{3-/ 4-}$. The surface area of BMCNTPS and PVLMCNTPS was determined using Randles-Ševčik formula [36]:

$$
I_{\mathrm{p}}=K n^{3 / 2} A D^{1 / 2} C_{0} v^{1 / 2}
$$

Here, $K$ is the constant equal to $2.69 \times 10^{5}\left(\mathrm{C} \mathrm{mol}^{-1} \mathrm{~V}^{-1 / 2}\right), I_{\mathrm{p}}$ is peak current $(\mathrm{A}), n$ is the number of transferred electrons, $A$ is effective surface area $\left(\mathrm{cm}^{2}\right), D$ is diffusion coefficient $\left(\mathrm{cm}^{2} \mathrm{~s}^{-1}\right)$, $v$ is voltage sweep rate $\left(\mathrm{Vs}^{-1}\right)$, and $C_{0}$ is concentration of $\left[\mathrm{Fe}(\mathrm{CN})_{6}\right]^{3-/ 4-}$ in $\mathrm{mol} \mathrm{cm}{ }^{-3}$. Using $n=1$ and $D=7.6 \times 10^{-6} \mathrm{~cm}^{2} / \mathrm{s}$ for $\left[\mathrm{Fe}(\mathrm{CN})_{6}\right]^{3-/ 4-}$, the calculated effective surface area of BMCNTPS and PVLMCNTPS was 0.034 and $0.13 \mathrm{~cm}^{2}$, respectively for $2 \mathrm{~mol} \mathrm{~cm}^{-3}\left[\mathrm{Fe}(\mathrm{CN})_{6}\right]^{3-/ 4-}$.

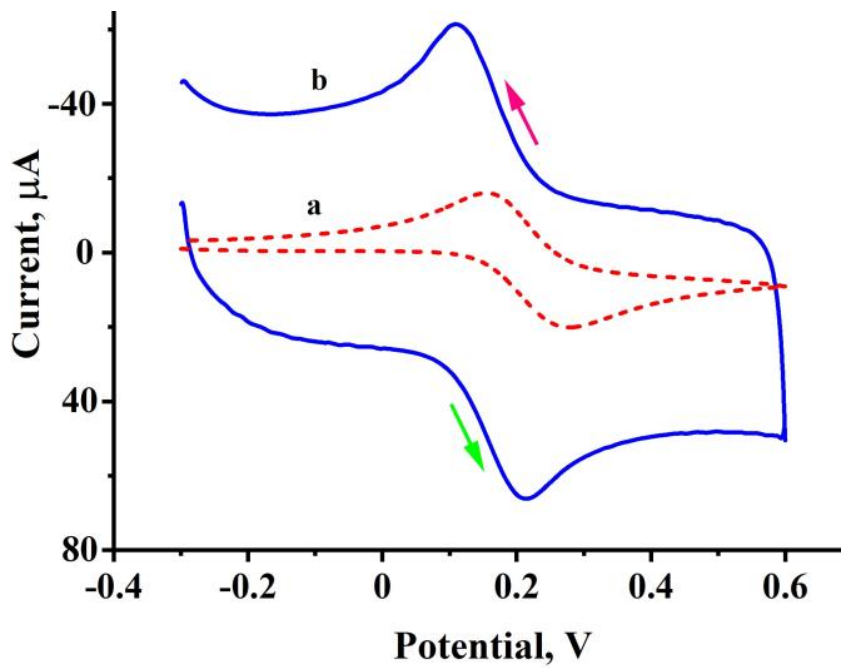

Figure 3. $C V$ responses $(0.1 \mathrm{~V} / \mathrm{s}$ ) of BMCNTPS (curve a) and PVLMCNTPS (curve b) in $0.1 \mathrm{M} \mathrm{KCl}$ containing $2 \mathrm{mM}\left[\mathrm{Fe}(\mathrm{CN})_{6}\right]^{3-14}$.

\section{Electrochemical oxidation of CTZ}

CV behavior of CTZ $(0.1 \mathrm{mM})$ was tested at BMCNTPS and PVLMCNTPS in PBS $(0.1 \mathrm{M}, \mathrm{pH} 7.0)$ at the sweep rate $0.1 \mathrm{~V} \mathrm{~s}^{-1}$, as exhibited in Figure 4. The curve a in Figure 4 represents CV of PVLMCNTPS for blank solution. Both BMCNTPS (curve b) and PVLMCNTPS (curve c) detect CTZ oxidation. BMCNTPS recognizes $C T Z$ at the oxidation potential of $0.89 \mathrm{~V}$ with poor current response, while 
PVLMCNTPS gives two superior signals at $0.765 \mathrm{~V}$ and $0.888 \mathrm{~V}$. At PVLMCNTPS, the current signal is five times higher and over-potential is reduced by $15.1 \%$ compared to BMCNTPS. Since CV of CTZ does not show a peak in the reverse scan, the CTZ process is considered irreversible.

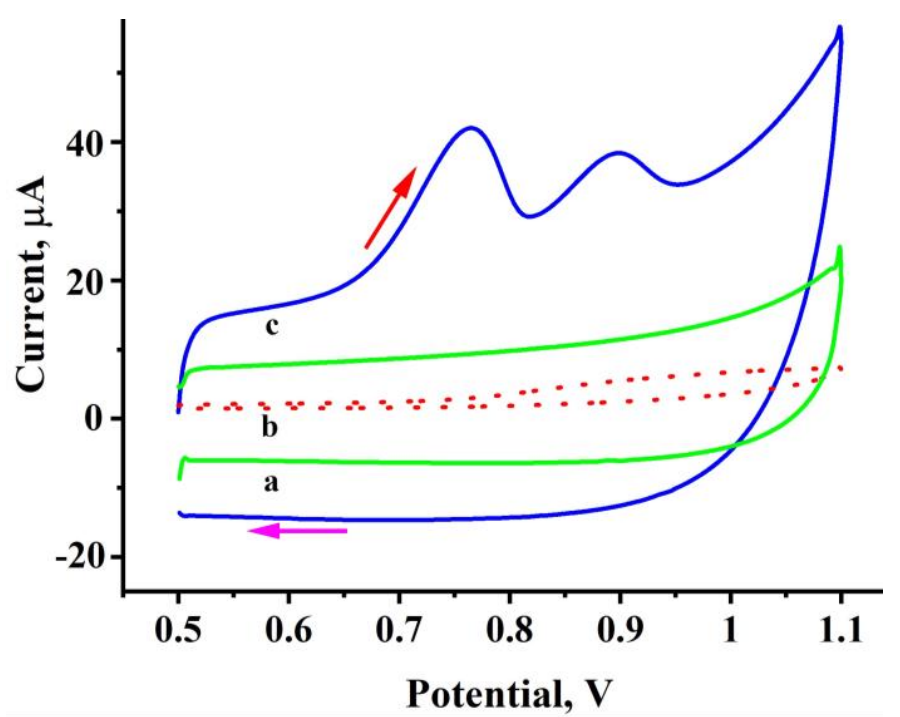

Figure 4. $C V$ responses $(0.1 \mathrm{~V} / \mathrm{s})$ of $C T Z(0.1 \mathrm{mM})$ in $0.1 \mathrm{M}$ PBS of $\mathrm{pH} 7.0$ at PVLMCNTPS (curve $\mathrm{c}$ ) and BMCNTPS (curve b) against blank solution at PVLMCNTPS (curve a).

\section{Effect of accumulation time}

Accumulation of analyte on electrode surface influences the electrode performance. The effect

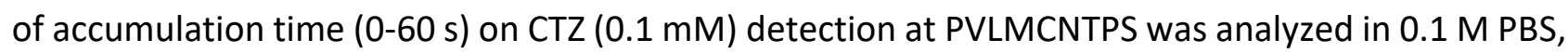
$\mathrm{pH}$ 7.0, as shown in Figure 5. The maximum current signal is achieved at $10 \mathrm{~s}$, whereas for further increases of accumulation time, peak currents were decreased. This is probably due saturation in accumulation of analyte on the sensor surface. Hence, $10 \mathrm{~s}$ of accumulation was optimized for further measurements.

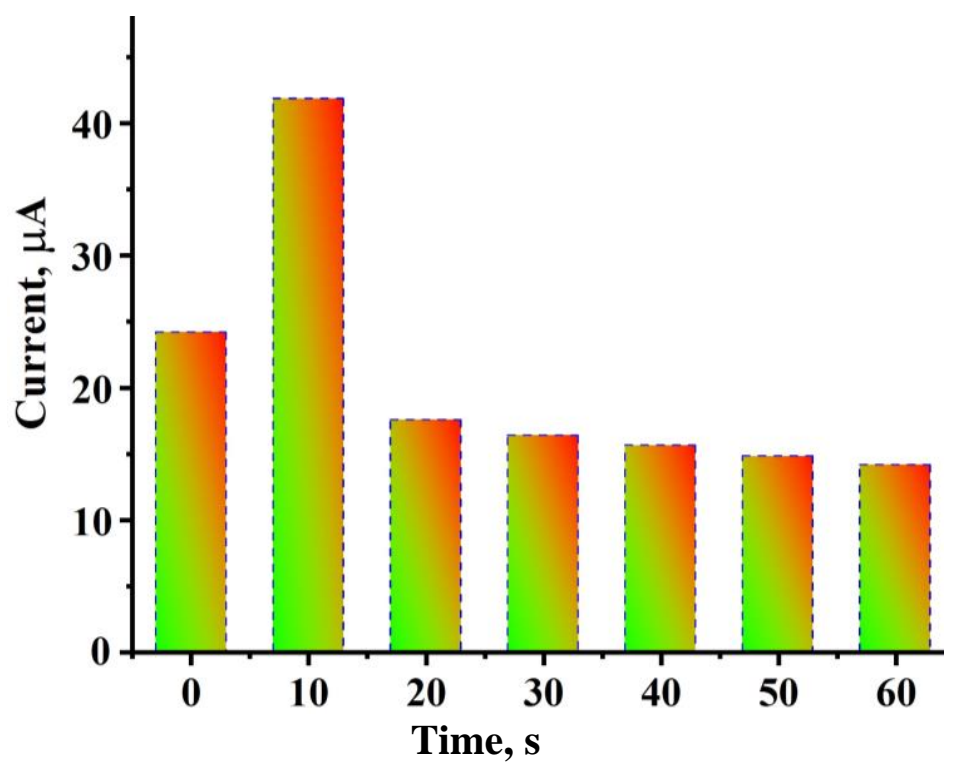

Figure 5. Effect of accumulation of time on CTZ $(0.1 \mathrm{mM})$ detection at PVLMCNTPS in $0.1 \mathrm{M} \mathrm{PBS}, \mathrm{pH} 7.0$ at $0.1 \mathrm{~V} / \mathrm{s}$ scan rate. 


\section{Sweep rate effect}

Influence of the potential scan rate was carried out in order to elucidate the kinetics of the process at the electrode-analyte interface. CVs as functions of sweep rate $(0.100-0.250 \mathrm{~V} / \mathrm{s})$ were recorded for CTZ oxidation in $0.1 \mathrm{M} \mathrm{PBS,} \mathrm{pH} \mathrm{7.0,} \mathrm{as} \mathrm{shown} \mathrm{in} \mathrm{Figure} \mathrm{6a.} \mathrm{The} \mathrm{peak} \mathrm{current} \mathrm{values} \mathrm{of}$ CTZ oxidation are increased with the change in the scan rate, while peak potential values are shifted towards more positive side. The plots of peak current vs. square root of the scan rate (Figure 6b), and log $I_{\text {pa }}$ against log scan rate (Figure $6 \mathrm{c}$ ) give clear evidence for diffusion process as per following equations:

$$
\begin{array}{ll}
I_{\mathrm{p}}=4.47 \times 10^{-6}+1.3467 \times 10^{-4} v^{1 / 2} & \mathrm{R}=0.99 \\
\log I_{\mathrm{p}}=0.56 \log v+2.12 & \mathrm{R}=0.99
\end{array}
$$

The number of electrons involved in the electrochemical oxidation of CTZ is calculated using the following equation [37]:

$$
E_{\mathrm{pa}}=E^{0}+\frac{R T}{(1-\alpha) n F} \ln v
$$

where $n$ is number of electrons involved, $R$ is gas constant $\left(8.314 \mathrm{~J} \mathrm{~K}^{-1} \mathrm{~mol}^{-1}\right), T$ is temperature, $F$ is Faraday's constant $\left(96,485 \mathrm{C} \mathrm{mol}^{-1}\right)$ and $\alpha$ is coefficient of charge transfer, assumed to be 0.5 for irreversible behaviour [38]. The number of electrons transferred for CTZ electro-oxidation was found to be $1.027 \approx 1$. The electron transfer mechanism of CTZ oxidation is sketched in Scheme 1 .
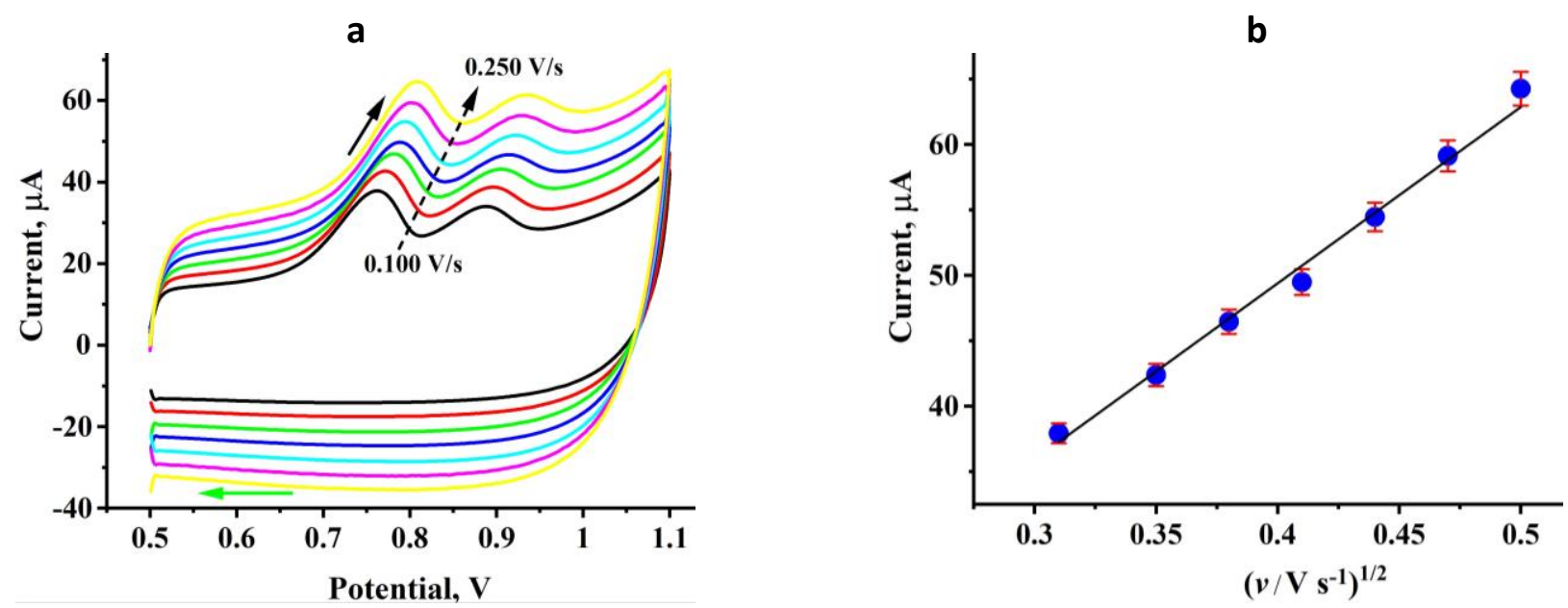

C

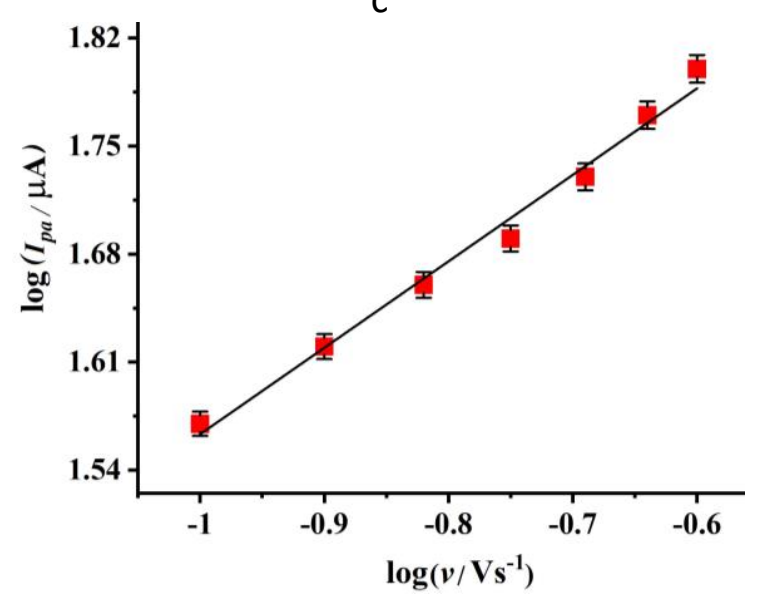

Figure 6. (a) CV responses at different sweep rates (0.100-0.250 V/s) for CTZ $(0.1 \mathrm{mM})$ at PVLMCNTPS in 0.1 M PBS, pH 7.0; (b) plot of peak current vs. $v^{1 / 2}$; (c) plot of log $I_{p a} v s . \log v$. 


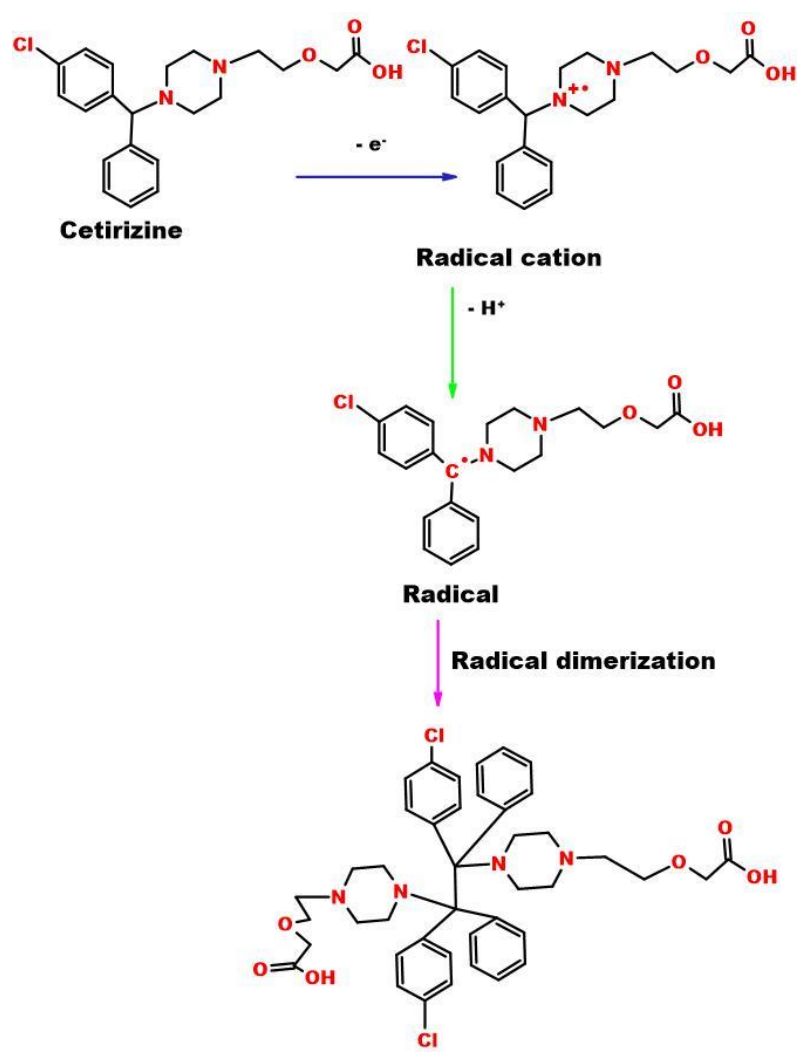

Scheme 1. Electron transfer mechanism of CTZ oxidation.

\section{Selection of $\mathrm{pH}$}

According to the given mechanism of CTZ oxidation, the electrochemical sensing is strongly affected by $\mathrm{pH}$ of the supporting electrolyte. The effect of $\mathrm{pH}$ changes from 5.5 to 7.5 on the sensing of CTZ $(0.1 \mathrm{mM})$ in $0.1 \mathrm{M}$ PBS at PVLMCNTPS is represented in Figure 7a. Obviously, the maximum anodic peak current $\left(I_{\mathrm{pa}}\right)$ of CTZ oxidation was obtained at pH 7.0. Hence, PBS with $\mathrm{pH} 7.0$ was chosen for further experimentation. As shown in Figure $7 \mathrm{~b}$, the plot of peak potential $\left(E_{\mathrm{pa}}\right)$ against buffer $\mathrm{pH}$ is found linear according to the following equation:

$$
E_{\mathrm{pa}}=1.126+0.051 \mathrm{pH} \quad(R=0.99)
$$

a

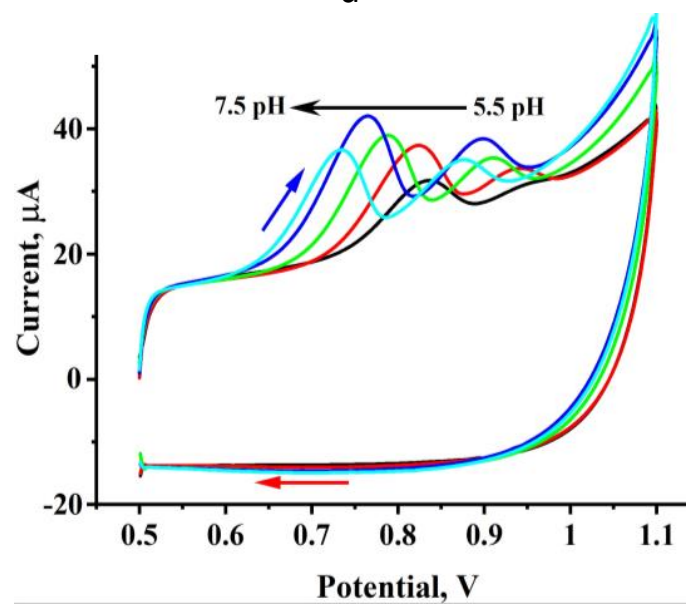

b

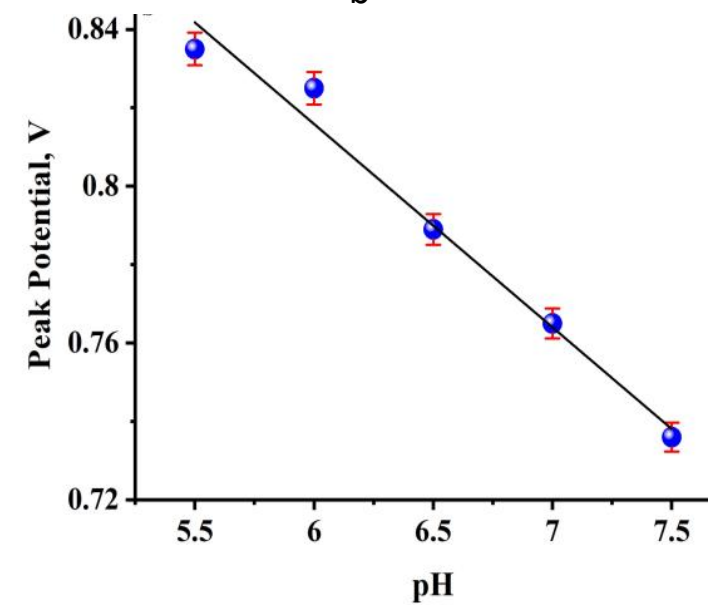

Figure 7. (a) CV responses (0.1 V/s) of CTZ (0.1 mM) at PVLMCNTPS in $0.1 \mathrm{M}$ PBS of different $p H$ (5.5-7.5);

(b) graphical plot of peak potential vs. $\mathrm{pH}$. 
From the linear plot in Figure $7 b$, the slope was estimated to be 0.051 , which is near the theoretical slope of 0.059 . This strongly suggests that the electrochemical oxidation of CTZ at PVLMCNTPS involves equal number of electrons and protons.

\section{Construction of calibration plot}

In order to determine the analytical performance of sensor, the effect of different concentrations of CTZ were studied by CV and shown in Figure 8a. As presented in Figure 8b, peak currents increased linearly with increase of the concentration of CTZ in the range 2.0-80 $\mu \mathrm{M}$. The linearity of curve is described as: $I_{\mathrm{p}} / \mathrm{A}=9.68 \times 10^{-6}+0.223 \mathrm{M}$ with $\mathrm{R}=0.99$. The detection limit (LOD) and limit of quantification (LOQ) values were found to be $0.11 \mu \mathrm{M}(3 \mathrm{~S} / \mathrm{N})$ and $0.372 \mu \mathrm{M}(10 \mathrm{~S} / \mathrm{N})$ [39], with sensitivity of $0.223 \mathrm{~A} / \mathrm{M}$.
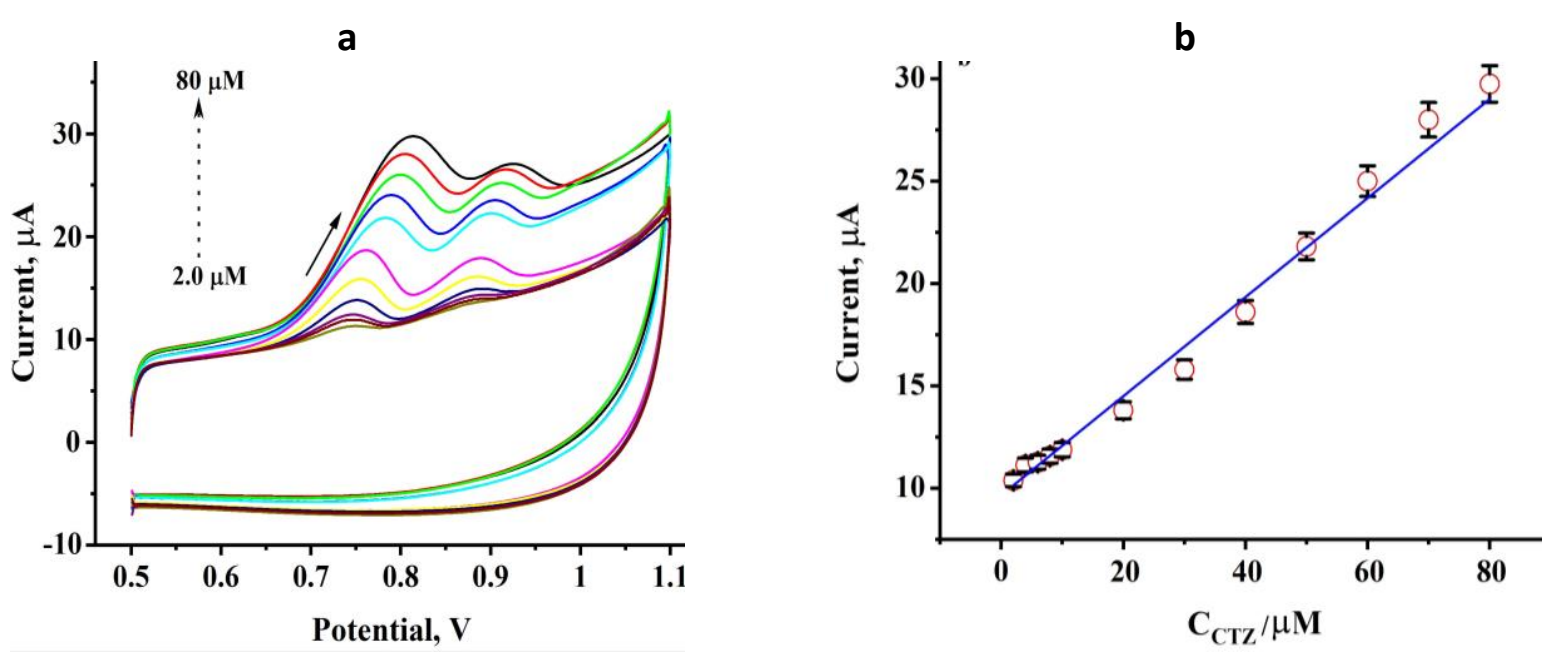

Figure 8. (a) $\mathrm{CV}$ responses (0.1 V/s) for CTZ concentrations from 2.0-80 $\mu \mathrm{M}$ at PVLMCNTPS in 0.1 M PBS, pH 7.0; (b) calibration plot of CTZ.

Table 1 presents a comparison of detection limit (LOD) values for CTZ determination of here proposed PVLMCNTPS with already existing sensors described in the literature [40-44]. It is clear that the obtained result for PVLMCNTPS is comparable with previous literature results.

Table 1. Comparison of obtained LOD values for CTZ determination at PVLMCNTPS with literature data on other electrochemical sensors.

\begin{tabular}{cccc}
\hline Electrochemical sensor & LOD, $\mu \mathrm{M}$ & Method of analysis & Reference \\
\hline $\begin{array}{c}\text { Glassy carbon electrode modified with } \\
\text { multiwalled carbon nanotubes }\end{array}$ & 0.071 & Cyclic voltammetry & {$[40]$} \\
\hline Glassy carbon electrode & 4.5 & Differential pulse voltammetry & {$[41]$} \\
\hline Carbon black / Glassy carbon electrode & 0.4 & $\begin{array}{c}\text { Square-wave adsorptive anodic } \\
\text { stripping voltammetry }\end{array}$ & {$[42]$} \\
\hline Pre-treated graphite pencil & 0.16 & Square wave voltammetry & {$[43]$} \\
\hline $\begin{array}{c}\text { Multi-walled carbon nanotube and } \\
\text { platinum nanoparticles nanocomposite } \\
\text { modified carbon paste electrode }\end{array}$ & 0.058 & $\begin{array}{c}\text { Adsorptive stripping differential } \\
\text { pulse voltammetry }\end{array}$ & {$[44]$} \\
\hline PVLMCNTPS & 0.118 & Cyclic voltammetry & Present work \\
\hline
\end{tabular}

Resolution of CTZ in presence of riboflavin (RF) and paracetamol (PC)

$\mathrm{CV}$ responses showing resolution of oxidation peaks for $0.1 \mathrm{mM}$ of $\mathrm{CTZ}, \mathrm{RF}$ and PC at BMCNTPS (dashed line) and PVLMCNTPS (solid line) are depicted in Figure 9. The BMCNTPS shows oxidation 
peaks for CTZ, RF and PC at $0.913,-0.592$ and $0.456 \mathrm{~V}$ with low current responses. PVLMCNTPS, however, exhibits enhanced current signals, showing clear peak separation for CTZ, RF and PC at $0.771,-0.472$ and $0.332 \mathrm{~V}$, respectively. This ultimately shows that analysis of CTZ in the mixture is more feasible at PVLMCNTPS than BMCNTPS.

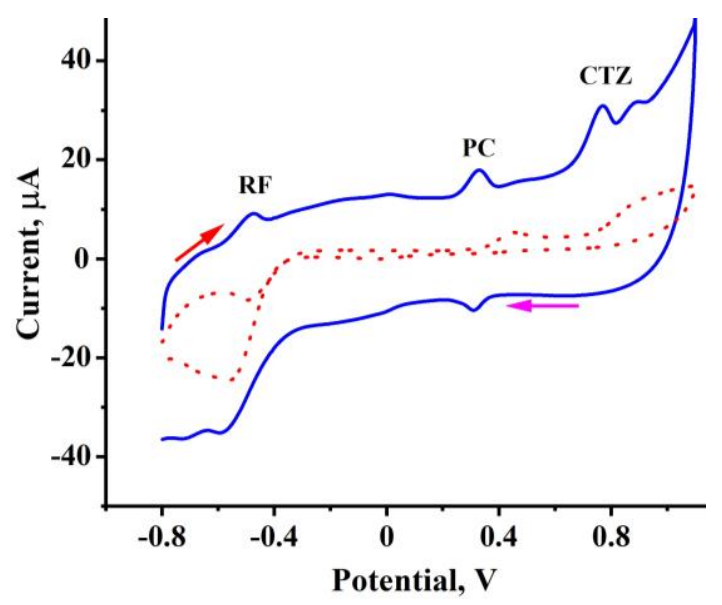

Figure 9. $C V$ responses $(0.1 \mathrm{~V} / \mathrm{s})$ showing simultaneous separation of $R F, P C$ and $C T Z(0.1 \mathrm{mM})$ oxidation peaks at PVLMCNTPS (solid line) and BMCNTPS (dashed line) in 0.1 M PBS, pH 7.0.

\section{Stability and reproducibility}

Reproducibility was tested at three newly formed PVLMCNTPS, where the results of CTZ determination were obtained with relative standard deviation (RSD) of $1.24 \%$. This RSD result shows good reproducibility of the prepared sensor. The stability of the proposed sensor was examined by keeping the sensor in a dry place for 24 hours prior CTZ detection. Even after 1 day of standing, the sensor provided $93.15 \%$ current retention for CTZ determination. This clarifies good storage stability of the proposed PVLMCNTPS.

\section{Selectivity}

To test reliability of the proposed PVLMCNTPS, the binding selectivity for $0.1 \mathrm{mM} \mathrm{CTZ} \mathrm{detection}$ in presence of various organic molecules such as ascorbic acid (AA), glucose (GU), riboflavin (RF), paracetamol $(P C)$, ciprofloxacin (CF), oxalic acid (OA), anthrone (AN), rhodamine (RH) $(0.1 \mathrm{mM})$ was tested in $0.1 \mathrm{M}$ PBS using CV technique. Figure 10 shows the change of peak potential $\left(E_{\mathrm{p}}\right)$ value of CTZ oxidation with addition of $0.1 \mathrm{mM}$ of each organic molecule. The results in Figure 10 suggest no significant interference of these organic molecules for CTZ detection, confirming thus the specificity of PVLMCNTPS.

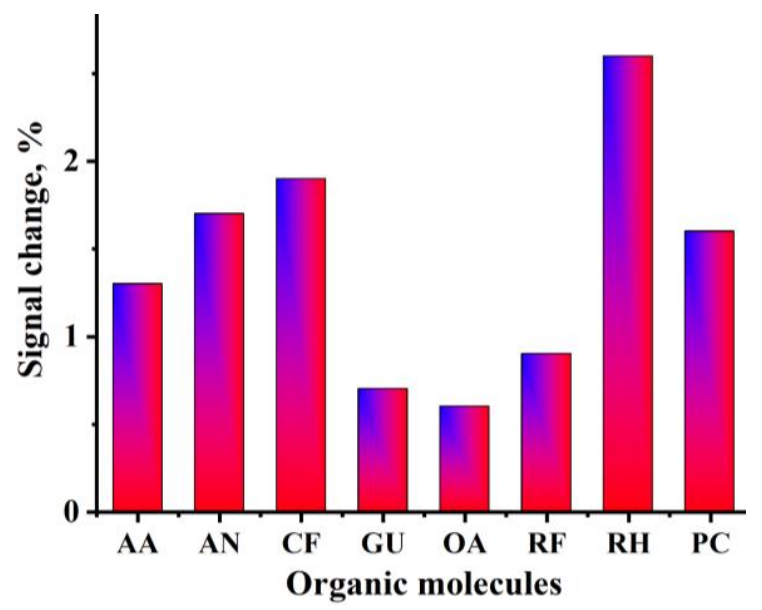

Figure 10. Graphical representation of effect of different organic molecules for detection of CTZ at PVLMCNTPS 


\section{CTZ tablet sample analysis}

To examine the practicability of the proposed strategy, PVLMCNTPS was utilized to detect CTZ concentration in CTZ tablets. CTZ tablets were firstly powdered uniformly using mortar and then 0.1 $\mathrm{mM} \mathrm{CTZ} \mathrm{solution} \mathrm{was} \mathrm{prepared} \mathrm{using} \mathrm{tablet} \mathrm{powder.} \mathrm{The} \mathrm{analysis} \mathrm{is} \mathrm{performed} \mathrm{in} 0.1 \mathrm{M} \mathrm{PBS,} \mathrm{pH} \mathrm{7.0}$ using the standard addition method. The results are given in Table 2, showing that CTZ recovery in the pharmaceutical product is obtained between 90-102.4\%.

Table 2. Real sample CTZ analysis and recovery at PVLMCNTPS.

\begin{tabular}{cccc}
\hline Sample & Amount of CTZ Added, $\mu \mathrm{M}$ & Amount of CTZ Found, $\mu \mathrm{M}$ & Recovery, \% \\
\hline \multirow{3}{*}{ CTZ tablet } & 8.0 & 7.20 & 90.0 \\
\cline { 2 - 4 } & 10.0 & 9.71 & 97.1 \\
\cline { 2 - 4 } & 20.0 & 20.48 & 102.4 \\
\hline
\end{tabular}

\section{Conclusions}

A simple and effective sensor for CTZ detection was prepared by electrochemical polymerization of DL-valine on the surface of multiwalled carbon nanotube paste sensor. The sensor modified by poly (DL-valine) has strong affinity towards CTZ molecules as compared to the unmodified sensor. The proposed CTZ sensor provides low detection limit of $0.11 \mu \mathrm{M}$ with good linear range of concentrations within 2-80 $\mu \mathrm{M}$. These results are either similar or even better than those obtained by already existing methods. Moreover, the proposed sensor is found stable, reusable, and specific for CTZ detection in presence of other interfering organic molecules, and also, very efficient for routine pharmaceutical analysis.

Acknowledgement: We gratefully acknowledge the financial support from VGST, Bangalore under Research project. No. KSTePS/VGST-KFIST (L1)2016-2017/GRD-559/2017-18/126/333, 21/11/2017.

\section{References}

[1] N. M. H. Rizk, S. S. Abbas, F. A. EL-Sayed, A. Abo-Bakr, International Journal of Electrochemical Science 4 (2009) 396-406.

[2] E. Baltes, R. Coupez, L. Brouwers, J. Gobert, Journal of Chromatography B: Biomedical Science and Applications 430 (1988) 149-155 https://doi.org/10.1016/S0378-4347(00)83145-X.

[3] M. Javanbakht, S. E. Fard, M. Abdouss, A. Mohammadi, M. R. Ganjali, P. Norouzi, L. Safaraliee, Electroanalysis 20 (2008) 2023-2030 https://doi.org/10.1002/elan.200804284.

[4] N. P. Shetti, S. J. Malode, D. S. Nayak, K. R. Reddy, Material Research Express 6 (2019) 115085 https://doi.org/10.1088/2053-1591/ab4b92.

[5] R. S. Kudchi, N. P. Shetti, S. J. Malode, A. B. Todakar, Materials Today: Proceedings 18 (2019) 558-565 https://doi.org/10.1016/j.matpr.2019.06.447.

[6] B. Uslu, S. A. Ozkan, Analytical Chemistry Letters 44 (2011) 2644-2702 https://doi.org/10.1080/00032719.2011.553010.

[7] L. Bajerski, M. D. Silva Sangoi, T. Barth, I. F. Diefenbach, S. L. Dalmora, S. G. Cardoso, Quimica Nova 33 (2010) 114-118.

[8] A. M. Y. Jaber, H. A. Al-Sherife, M. M. Al-Omari, A. A. Badwan, Journal of Pharmaceutical and Biomedical Analysis 36 (2004) 341-350 https://doi.org/10.1016/j.jpba.2004.07.002.

[9] B. G. Gowda, M. B. Melwanki, J. Seetharamappa, Journal of Pharmaceutical and Biomedical Analysis 25 (2001) 1021-1026 https://doi.org/10.1016/S0731-7085(01)00395-8.

[10] M. Ming, F. Fang, S. Yulan, C. Shuangjin, L. Han, Journal of Chromatography B 846 (2007) 105-111 https://doi.org/10.1016/i.jchromb.2006.08.026.

[11] M. B. Melwanki, J. Seetharamappa, B. G. Gowda, A. G. Sajjan, Chemia Analityczna 46 (2001) 883-887.

[12] E. Culkova, Z. Lukacova-Chomistekova, R. Bellova, D. Melichercikova, J. Durdiak, J. Timko, International Journal of Electrochemical Science 13 (2018) 6358-6372 https://doi.org/10.20964/2018.07.42. 
[13] N. P. Shetti, S. J. Malode, D. S. Nayak, T. M. Aminabhavi, K. R. Reddy, Microchemical Journal 150 (2019) 104124 https://doi.org/10.1016/i.microc.2020.104945.

[14] C. Li, J. Fu, X. Tan, X. Song, Q. Li, Analytical Methods 11 (2019) 4099-4105 https://doi.orgL10.1039/C9AY01018A.

[15] M. M. Charitra, J. G. Manjunatha, C. Raril, Advanced Pharmaceutical Bulletin 10 (2020) 247-253 https://doi.org/10.34172/apb.2020.029.

[16] G. Tigari, J. G. Manjunatha, Monatshefte für Chemie-Chemical Monthly 151 (2020) 1681-1688 https://doi.org/10.1007/s00706-020-02700-8.

[17] J. G. Manjunatha, Asian Journal of Pharmaceutical and Clinical Research 10 (2017) 295-300.

[18] J. G. Manjunatha, M. Deraman, N. H. Basri, Asian Journal of Pharmaceutical and Clinical Research 8 (2015) 48-53.

[19] B. M. Amrutha, J. G. Manjunatha, A. S. Bhatt, C. Raril, P. A. Pushpanjali, Physical Chemistry Research 7 (2019) 523-533 https://10.22036/pcr.2019.185875.1636.

[20] N. S. Prinith, J. G. Manjunatha, C. Raril, Analytical and Bioanalytical Electrochemistry 11 (2019) 742756.

[21] C. B. Jacobs, M. J. Peairs, B. J. Venton, Analytica Chimica Acta 662 (2010) 105-127 https://doi.org/10.1016/j.aca.2010.01.009.

[22] G. Tigari, J. G. Manjunatha, Instruments and Experimental Techniques 63 (2020) 750-757 https://doi.org/10.1134/S0020441220050139.

[23] N. Anzar, R. Hasan, M. Tyagi, N. Yadav, J. Narang, Sensors International 1 (2020) 100003 https://doi.org/10.1016/i.sintl.2020.100003

[24] A. Venkataraman, E. V. Amadi, Y. Chen, Y. C. Papadopoulos, Nanoscale Research Letters 14 (2019) 220. https://doi.org/10.1186/s11671-019-3046-3.

[25] J. M. Zen, A. S. Kumar, D. M. Tsai, Electroanalysis 15 (2003) 1073-1087 https://doi.org/10.1002/elan.200390130

[26] P. K. Kalambate, A. K. Srivastava, Sensors and Actuators B: Chemical 233 (2016) 237-248 https://doi.org/10.1016/j.snb.2016.04.063.

[27] S. Tajik, H. Beitollahi, F. G. Nejad, M. Safaei, K. Zhang, Q. V. Lee, R. S. Verma, H. W. Jang, M. Shokouhimehr, RSC Advances 10 (2020) 21561 https://doi.org/10.1039/d0ra03672b.

[28] G. K. Jayaprakash, B. E. Kumara Swamy, H. N. G. Ramirez, T. M. Ekanthappa, R. Flores Moreno, New Journal of Chemistry 42 (2018) 4501-4506 https://doi.org/10.1039/C7NJ04998F.

[29] S. Sharath Shankar, B. E. Kumara Swamy, B. N. Chandrashekar, K. J. Gururaj, Journal of Molecular Liquids 177 (2013) 32-39 https://doi.org/10.1016/j.molliq.2012.10.002.

[30] G. Tigari, J. G. Manjunatha, Journal of Analysis and Testing 3 (2019) 331-340 https://doi.orgL10.1007/s41664-019-00116-w.

[31] B. N. Chandrashekar, B. E. Kumara Swamy, K. J. Gururaj, C. Cheng, Journal of Molecular Liquids 231 (2017) 379-385. https://doi.org/10.1016/j.molliq.2017.02.029

[32] G. K. Jayaprakash, R. Flores-Moreno, Electrochimica Acta 248 (2017) 225-231 https://doi.org/10.1016/j.electacta.2017.07.109.

[33] G. K. Jayaprakash, B. E. Kumara Swamy, J. P. M. Sanchez, X. Li, S. C. Sharma, S. Lee, Journal of Molecular Liquids 315 (2020) 113719. https://doi.org/10.1016/i.molliq.2020.113719

[34] J. G. Manjunatha, M. Deraman, Analytical and Bioanalytical Electrochemistry 9 (2017) 198-213.

[35] G. K. Jayaprakash, B. E. Kumara Swamy, N. Casillas, R. Flores-Moreno, Electrochimica Acta 258 (2017) 1025-1034 https://doi.org/10.1016/i.electacta.2017.11.154.

[36] E. S. D' Souza, J. G. Manjunatha, C. Raril, G. Tigari, Journal of Material and Environmental Science 11 (2020) 512-521.

[37] C. Raril, J. G. Manjunatha, Journal of Material and Environmental Science 10 (2019) 510-519.

[38] A. Sangili, P. Veerakumar, S. M. Chen, C. Rajkumar, K. C. Lin, Microchimica Acta 186 (2019) 299 https://doi.org/10.1007/s00604-019-3396-7.

[39] H. Beitollahi, S Tajik, S.Z. Mohammadi, M. Baghayeri, lonics 20 (2014) 571-579 https://doi.org110.1007/s11581-013-1004-0.

[40] R. H. Patil, R. N. Hegde, S. T. Nandibewoor, Colloids and Surfaces B: Biointerfaces 83 (2011) 133-138 https://doi.org/10.1016/j.colsurfb.2010.11.008.

[41] S. D. Gungor, Die Pharmazie 59 (2004) 929-933. 
[42] B. C. Lourencao, T. A. Silva, M. S. Santos, A. G. Ferreira, O. Fatibello-Filho, Journal of Electroanalytical Chemistry 807 (2017) 187-195 https://doi.org/10.1016/i.jelechem.2017.11.013.

[43] S. Karakaya, D. G. Dilgin, Monatshefte fur Chemie 150 (2019) 1003-1010 https://doi.org/10.1007/s00706-019-2384-2.

[44] P. K. Kalambate, A. K. Srivastava, Sensors and Actuators B: Chemical 233 (2016) 237-248 https://doi.org/10.1016/j.snb.2016.04.063.

(C2021 by the authors; licensee IAPC, Zagreb, Croatia. This article is an open-access article distributed under the terms and conditions of the Creative Commons Attribution license (https://creativecommons.org/licenses/by/4.0/) 